\title{
Age distribution and associated factors of cornea biomechanical parameter stress- strain index in Chinese healthy population
}

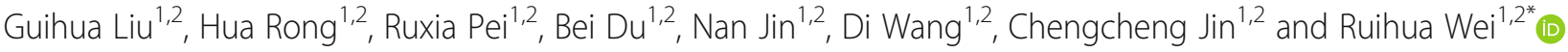

\begin{abstract}
Background: To investigate the new cornea biomechanical parameter stress-strain index (SSI) in Chinese healthy people and the factors associated with SSI.

Methods: A total of 175 eyes from 175 participants were included in this study. Axial length was measured with the Lenstar LS-900. Pentacam measured curvature of the cornea and anterior chamber volume (ACV). Cornea biomechanical properties assessments were performed by corneal visualization Scheimpflug technology (Corvis ST). Student's t-test, one-way ANOVA, partial least square linear regression (PLSLR) and linear mixed effects (LME) model were used in the statistical analysis.

Results: The mean ( \pm SD) SSI was $1.14 \pm 0.22$ (range, 0.66-1.78) in all subjects and affected by age significantly after age of $35(P<0.05)$. In LME models, SSI was significantly associated with age $(\beta=0.526, P<0.001)$, axial length (AL) $(\beta=-0.541, P<0.001)$, intraocular pressure (IOP) $(\beta=0.326, P<0.001)$ and steepest radius of anterior corneal curvature (RsF) $(\beta=0.229, P<0.001)$ but not with $A C V$, biomechanical corrected intraocular pressure (blOP), flattest radius of anterior corneal curvature (RfF) or central corneal thickness (CCT) ( $P>0.05$ for each).

Conclusions: SSI increased with age after the age of 35. In addition to age, SSI was positively correlated with RsF and IOP, while negatively correlated with AL.
\end{abstract}

Keywords: Corvis ST, Corneal biomechanics, Anterior segment parameters, Stress-strain index, Chinese population

\section{Background}

Corneal biomechanical determination is of great importance in clinical evaluation, such as diagnosis of keratoconus [1], assessment before corneal refractive surgery [2, $3]$, and measurement of corrected intraocular pressure $[4,5]$. In recent years, various instruments that measured corneal biomechanics were developed, such as ocular response analyzer (ORA) and Corvis ST. Meanwhile, a variety of parameters to assess corneal biomechanics were

\footnotetext{
* Correspondence: rwei@tmu.edu.cn

${ }^{1}$ Tianjin International Joint Research and Development Centre of Ophthalmology and Vision Science, Postal address: 251 Fukang Road, Nankai District, Tianjin, China

${ }^{2}$ Eye Institute and School of Optometry, Tianjin Medical University Eye Hospital, Postal address: 251 Fukang Road, Nankai District, Tianjin, China
}

provided. However, since cornea consists of a viscoelastic material, and its stress-strain behavior of biological tissue is nonlinear $[6,7]$, the cornea shows the biomechanical properties of changes under different intraocular pressure load. Hon reported a corneal indentation device (CID) that can measure the stiffness (S) and tangent modulus (E) of the cornea in vivo, but $\mathrm{S}$ and $\mathrm{E}$ due to IOP rise could not be ruled out $[8,9]$. It was always a difficult problem to evaluate corneal biomechanics without the influence of IOP in vivo [10-12].

A new method to obtain the stiffness of corneal material was proposed by Eliasy, which eliminated central corneal thickness (CCT) and biomechanical corrected intraocular pressure (bIOP) in vivo [10]. A biomechanical Corvis

C C The Author(s). 2020 Open Access This article is licensed under a Creative Commons Attribution 4.0 International License, which permits use, sharing, adaptation, distribution and reproduction in any medium or format, as long as you give appropriate credit to the original author(s) and the source, provide a link to the Creative Commons licence, and indicate if changes were made. The images or other third party material in this article are included in the article's Creative Commons licence, unless indicated otherwise in a credit line to the material. If material is not included in the article's Creative Commons licence and your intended use is not permitted by statutory regulation or exceeds the permitted use, you will need to obtain permission directly from the copyright holder. To view a copy of this licence, visit http://creativecommons.org/licenses/by/4.0/ The Creative Commons Public Domain Dedication waiver (http://creativecommons.org/publicdomain/zero/1.0/) applies to the data made available in this article, unless otherwise stated in a credit line to the data. 
parameter, stress-strain index (SSI) has been proved to be almost independent of bIOP and CCT. It was shown as an ideal method to estimate the mechanical properties of corneal tissue material. The distribution of SSI in Italian and Brazilian populations has been reported by previous studies and SSI was found to be significantly affected by age [10]. Chua observed that there was a lower corneal hysteresis $(\mathrm{CH})$ in Chinese than Indians, suggesting that corneal biomechanics may be varies among different populations [13]. At present, the SSI distribution of different age in Chinese population has not been reported.

Corneal stiffness is one of the important biomechanical parameters, which reflects the ability to resist stress deformation [14]. Previous studies have shown that corneal biomechanics could be affected by multiple factors. A larger anterior chamber volume (ACV) was associated with a lower maximum amplitude at the apex of highest concavity (DA) and a higher stiffness parameter (SP-A1) in primary angle closure (PAC) eyes [15]. In healthy people, corneal biomechanical parameters were significantly correlated with the corneal curvature, refractive error $[16,17]$ but not with ACV [18]. However, Lim found that corneal biomechanics was not associated with age, refraction error, but related to CCT, corneacompensated intraocular pressure (IOPcc) and anterior curvature [19]. While other factors that may influence SSI besides age have not been reported. Therefore, the purpose of this study is to explore the distribution of SSI in different age in healthy Chinese population and investigate the factors associated with SSI via Corvis ST.

\section{Methods}

\section{Subjects}

This was a prospective study on healthy eye cornea biomechanics. A total of 175 patients aged 5 to 74 years were recruited between May and June 2020 in Tianjin Medical University Eye Hospital. Written informed consent was obtained from all enrolled participants or their parents or guardians where participants were children (under 16 years old). All examinations conducted in accordance with the tenets of the Declaration of Helsinki and approved by Tianjin Medical University Eye Hospital ethics committee.

All patients underwent a complete ophthalmic examination, including visual acuity, slit-lamp ophthalmic examination, intraocular pressure, and fundus examination. Exclusion criteria included any corneal pathology, keratoconus, contact lens use, refractive surgery, uveitis, allergic eye disease, glaucoma or retinal disease, history of intraocular surgery, and any significant systemic illnesses. Patients with refractive error $<-10 \mathrm{D}$ were excluded.

\section{Axial length}

Axial length was measured with a non-contact biometer (Lenstar LS-900; Haag-Streit AG, Berne, Switzerland).
Subjects were asked to keep both eyes open and fixate on the target. Between measurements, the subject was instructed to blink several times to make sure an intact tear film to prevent potential measurement errors. Three repeated measurements of the axial length were carried out and intra-session differences of no greater than 0.02 $\mathrm{mm}$ were averaged for data analysis.

\section{Curvature and ACV}

Pentacam (Oculus, Wetzlar, Germany) was used to measure the curvature of cornea and ACV. All measurements were performed in a dark room. Patients were instructed to blink briskly before measurements taken and keep eyes widely open during scanning while fixating on the target. Only measurements which obtained an 'OK' quality index were saved.

\section{Biomechanical parameters}

The cornea biomechanical properties were measured by Corvis-ST (Oculus, Wetzlar, Germany), which is a noncontact tonometer equipped with an optical pachymetry function. The corneal response to an air-puff pulse was recorded with 4330 images per second by a built-in high-speed camera. The following parameters were detected by Corvis ST: IOP, bIOP, CCT and the new parameter SSI. SSI is a parameter established to eliminate the interference of bIOP and corneal geometry and estimate the stiffness of the material, which is different from the stiffness parameter (SP). SSI algorithm was based on the prediction of cornea behavior by using the finite element numerical modeling simulation of the influence of IOP and Corvis ST air puff on cornea behavior. Only the quality index was 'OK' were included in the analysis.

\section{Statistical analysis}

Statistical analyses were accomplished using SPSS statistical package 25 (SPSS, IBM, Chicago, IL, USA). Paired t-test was performed to explore the inter-ocular difference of SSI. There was no significant difference of SSI between the bilateral eyes $(P>0.05)$, thus, only left eyes were included in the subsequent analysis to avoid the bias of the relationship between bilateral eyes. Kolmogorov-Smirnov was used for testing the normal distribution of the data. The Student's t-test was used to compare SSI between males and females. The sample population was divided into seven age groups by tenyear intervals ranging from 5 to 14 years to $65-74$ years old. The differences among the subgroups according to age were compared using one-way ANOVA and the LSD. Because there were strong correlations between predictor variables, partial least square linear regression (PLSLR) was performed first, followed by linear mixed effects (LME) to reveal the relationship between SSI and 
clinical parameters. $P<0.05$ was considered as statistically significant.

\section{Results}

A total of 175 left eyes from 175 healthy patients who met the study inclusion criteria were analyzed. Among of them, 75 (42.9\%) were male and $100(57.1 \%)$ were female. SSI showed a normal distribution $(P>0.05)$. There were no significant gender differences existed in SSI $(\mathrm{P}>0.05)$. The data are summarized in Table 1.

The average SSI was $1.14 \pm 0.22$ in all subjects and the values ranged from 0.66 to 1.78 . To explore the differences of corneal stiffness between different age groups, patients were divided into seven groups according to age (Fig. 1). A significant rising trend was found in SSI with age increasing significantly after age of $35(P<0.05)$.

Due to the high correlation between the measurements, PLSLR and LME analysis was used to find the correlation between SSI and other parameters. After PLSLR calculation, five parameters were left, which were IOP, bIOP, AL, age and RsF, and then they were put into the LME model. The results showed that SSI was positively correlated with age, RsF and IOP, while it was negatively correlated with AL (Table 2).

\section{Discussion}

This study described the distribution of corneal tissue material stiffness parameter SSI in different age groups and related factors in a healthy Chinese population. We found that SSI was relatively stable before age of 35 , and then increased significantly with age. SSI was positively correlated with age, IOP, and anterior radius of curvature, meanwhile, it was negatively correlated with axial length. No significant effect was found in gender, ACV, CCT, or bIOP.

Table 1 Demographic and clinical characteristics of the study groups. $N=175$

\begin{tabular}{llll}
\hline Parameters & Mean & SD & $\mathbf{9 5 \% C l}$ \\
\hline SSI & 1.14 & 0.22 & $1.11-1.17$ \\
Age, years & 37.06 & 16.91 & $34.53-39.58$ \\
AL, mm & 24.47 & 1.68 & $24.22-24.73$ \\
IOP, mmHg & 14.91 & 1.62 & $14.67-15.15$ \\
blOP, mmHg & 14.36 & 1.56 & $14.13-14.59$ \\
RfF, mm & 7.85 & 0.26 & $7.81-7.89$ \\
RsF, mm & 7.62 & 0.26 & $7.58-7.66$ \\
ACV, mm & 167.75 & 44.07 & $161.18-174.33$ \\
CCT, $\mu m$ & 552.20 & 28.18 & $548.00-556.40$
\end{tabular}

Data were expressed as mean \pm standard deviation

SSI Stress-Strain index, AL Axial length, IOP Intraocular pressure, bIOP Biomechanical corrected intraocular pressure, RfF Flattest radius of anterior corneal curvature, RsF Steepest radius of anterior corneal curvature, ACV Anterior chamber volume, CCT Central corneal thickness, SD Standard deviation, $\mathrm{Cl}$ Confidence interval
In our study, a nonlinear relationship was detected between age and SSI, showing that SSI increased with age significantly after age of 35 . Age has been shown to be an important factor affecting corneal biomechanical in previous study [10]. Wang found a positive correlation between age and second applanation (A2L) in healthy Chinese adults [20]. In corneas of patients aged from 50 to 95 years, the tangent modulus increased with age [7]. Trend of corneal biomechanics with age could be accounted for changes in the molecular structure in cornea. Daxer and Malik observed that non-enzymatic crosslinking, collagen glycation, fibril diameter, and the number of collagen molecules increased with age over 40 years in corneal X-ray [21-23]. These could explain the reason that SSI increased with age after 35 . However, we found that SSI was basically stable before the age of 35. In previous studies, Kirwan used ORA to measure corneas of normal children aged 4 to 18 years, and found that $\mathrm{CH}$ was not correlated with age [24]. Another study found that there was no significant correlation between biomechanical parameters and age in healthy Chinese adolescents at 4-18 years of age [25]. Valbon found that deformation amplitude (DA) and other biomechanical parameters of the healthy eyes in population under 40 years old were not correlated with age [26]. Elsheikh measured the corneal tangent modulus (E) in vitro for 30-99 years old, and found that the growth rate of $\mathrm{E}$ was smaller in the younger, which also suggested that the changes in corneal biomechanics may be uneven with age [27]. Unfortunately, few studies have reported the relationship between corneal collagen and age in young people. Whether this relationship is the reason that no significant correlation is revealed between SSI and age in the young remains to be explored. Furthermore, the AL and refractive error increase with age in young people [28]. We speculate those may reduce the tendency of the cornea to harden with age. This inference needs to be further proved in future studies.

SSI was found to be negatively correlated with axial length, which indicated that the SSI includes a function of the whole eye biomechanics and not just the cornea. Previous studies indicated that the cornea and sclera were mainly composed of the same types of collagen [29]. In addition, when the collagen fibers of the sclera became longer and damaged in myopia progression, the overall arrangement of collagen fibers in corneal stroma also restructured [30-32]. In infant monkeys and chicks, corneal astigmatism changes were also associated with induced eye growth $[33,34]$. Chang's study pointed out that the axial elongation led to corneal flattening and thickness reduction [35], suggesting that the increase of axial length may affect the biomechanics of the cornea and previous studies have proved this. Myopia in glaucoma and normal eyes would lead to biomechanical 


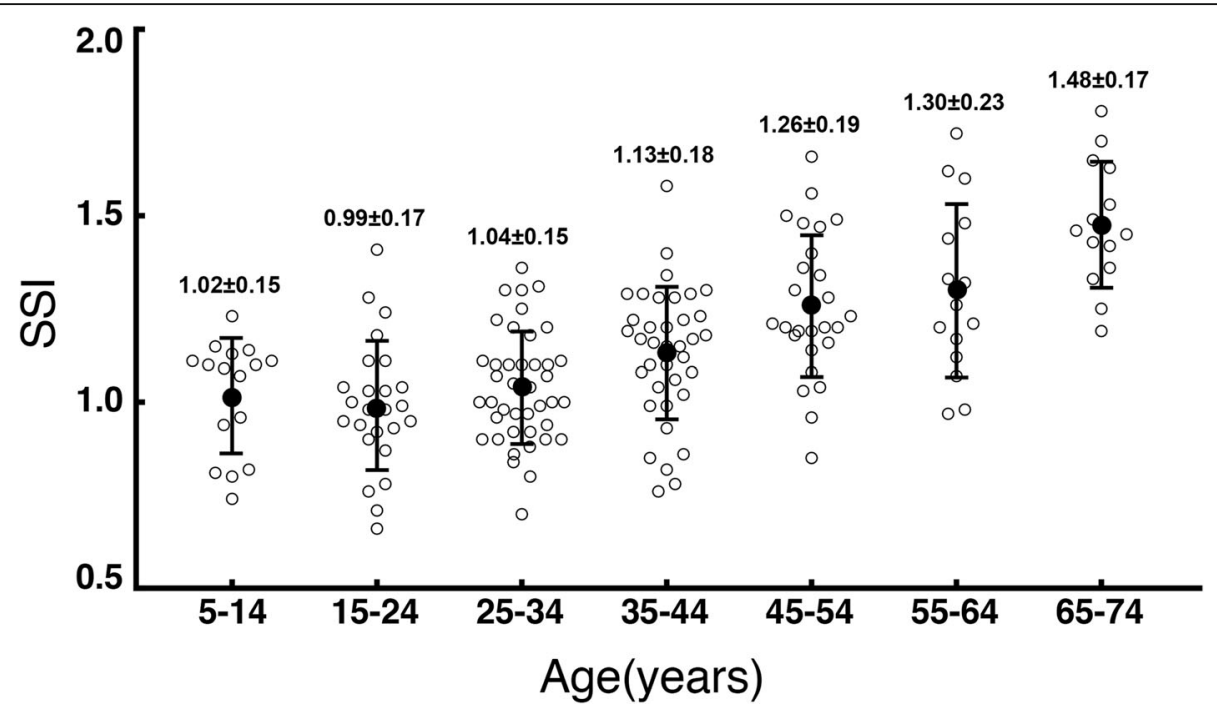

Fig. 1 Mean values of the biomechanical parameters SSI for all subgroups according to age and shows the variation by age (ANOVA)

parameters changes such as corneal deformation amplitude (CDA), outward corneal applanation (OCA) and cornea stiffness (CS) [36, 37]. Especially the cornea in high myopia had faster outward corneal velocity (OCV) and higher CDA compared to emmetropia [16]. Long found in Chinese children, SP - A1 declined gradually between presbyopia, emmetropia and myopia groups [38]. However, in Lim's study, CH and CRF were not significantly correlated with refractive errors by ORA measurement in corneal biomechanics in children aged 7-9 years. Lim believed the possible reason was the brief loading-unloading cycle of the ORA contrasts with the slower profile of scleral creep experiments and myopic deformation [19]. Actually, ORA exams $\mathrm{CH}$ or energy absorption but not corneal shape at maximum concavity. It may be more corneal specific and less surrounding

Table 2 Coefficients ( $\beta$ ) and $P$-value in LME models between each analysed variable and SSI

\begin{tabular}{lll}
\hline Parameters & LME model & \\
\cline { 2 - 3 } & $\boldsymbol{\beta}$ & $\boldsymbol{P}$ \\
\hline Age, years & 0.526 & $<0.001^{*}$ \\
AL, mm & -0.541 & $<0.001^{*}$ \\
IOP, mmHg & 0.326 & $<0.001^{*}$ \\
RsF, mm & 0.229 & $<0.001^{*}$ \\
blOP, mmHg & 0.070 & 0.445 \\
\hline
\end{tabular}

*Statistically significant

AL Axial length, IOP Intraocular pressure, RsF Steepest radius of anterior corneal curvature, bIOP Biomechanical corrected intraocular pressure, $\beta$ Standardized coefficients;

The adjusted $R^{2}$ value of this $L M E$ model was $0.668 . P<0.05$ considered statistically significant affected and possibly buttressing sclera [14]. This may be the reason that biomechanical parameters measured by ORA are not correlated with refractive errors.

Consistent with the study of Eliasy, neither bIOP nor CCT was significantly correlated with $\mathrm{SSI}^{10}$, but SSI was found to be positively correlated with IOP. It was not surprising, since SSI reflected the corneal stiffness, and IOP measurement was affected by corneal stiffness [12, 39]. While it was emphasized that bIOP can exclude the influence of corneal thickness and age on intraocular pressure measurement [40], and can reflect more accurate intraocular pressure [41-43]. Besides IOP, previous studies have shown that, parameters of corneal biomechanics in vivo were mostly affected by bIOP such as deflection area at the highest concavity and deflection amplitude (HC DefArea and HC DefA), SP - A1 [43], $\mathrm{CH}$ and CRF [44]. However, SSI based on finite element (FE) numerical modeling simulats the effects of Corvis ST air puff and bIOP to predict of corneal behavior and excludes the influence of bIOP, indicating that this is an ideal method for in vivo measurement of corneal tissue material stiffness [10].

There was no significant correlation between SSI and ACV in LME model. The results of this study were consistent with Gabor Nemeth and Hwang, that the ACV was not significantly related to biomechanical parameters $[18$, 45]. Cui's study pointed out that decrease in ACV led to reduced corneal stiffness in the PAC suspects. This could be explained by the different population in the studies. Cui believed that the stiffness of cornea would reduce in PAC and compensated for the high IOP caused by the shallow anterior chamber [15]. But in healthy people, there was no significant effect of ACV on corneal stiffness. 
This study found that the radius of anterior curvature was positively correlated with SSI. There has been controversy on the relationship between corneal curvature and biomechanics. It was found that SP-A1 was positively correlated with corneal asphericity ( $\mathrm{Q}$ value) and radius of anterior surface [46]. In Nemeth's study, the corneal curvature was also related to the amplitude of corneal deformation and the time taken to reach this applanation [18]. On the contrary, several studies found that there was no significant correlation between the curvature and $\mathrm{CH}$ or $\mathrm{CRF}[45,47,48]$. The correlation between corneal curvature and biomechanics needs further study.

Our research had several limitations. Firstly, SSI was currently estimated with normal corneal topography, which could not be applied in corneas with biomechanical decline caused by pathological changes. The calculation method of corneas with keratoconus or ectasia needs to be further developed. Secondly, the relationship between refractive error and SSI was not analyzed. Previous studies have pointed out that refractive error was highly correlated with the axial length of the eye [49], and it has also been shown that the extension of the axial length had a significant correlation with the sclera and cornea tissue structure [32]. Therefore, we considered that the axial length was more significant as an evaluation factor.

\section{Conclusions}

In conclusion, this study for the first time conducted a statistical analysis of SSI in a healthy Chinese population and found that SSI was positively correlated with RsF, IOP and negatively correlated with AL. Moreover, after the age of 35, SSI increased with age.

\footnotetext{
Abbreviations

Corvis ST: Corneal visualization Scheimpflug technology; AL: Axial length; IOP: Intraocular pressure; bIOP: Biomechanical corrected intraocular pressure; RfF: Flattest radius of anterior corneal curvature; RsF: Steepest radius of anterior corneal curvature; ACV: Anterior chamber volume; CCT: Central corneal thickness
}

\section{Acknowledgements}

Not applicable.

\section{Authors' contributions}

RHW conceived and supervised the experiment. BD and DW performed the study. RXP and CCJ collected the data, and NJ analyzed the data. GHL and HR wrote the manuscript. GHL and HR contributed equally to this work and were both considered first authors. All authors read and approved the final manuscript.

\section{Funding}

This study was supported by grants from by the National Natural Science Foundation of China (No. 81770901). The funding organization had no role in the design or conduct of this research.

\section{Availability of data and materials}

Data and materials are available upon request from the corresponding author at rwei@tmu.edu.cn.

\section{Ethics approval and consent to participate}

This study was approved by the Human Research Ethics Committee of Tianjin Medical University Eye Hospital and was conducted in accordance with the Declaration of Helsinki. Written informed consent was obtained from all enrolled participants or their parent or guardian where participants are children (under 16 years old). The study was registered on April 30, 2020 (HTTP://www.chictr.org.cn Registration number: ChiCTR2000032444).

\section{Consent for publication}

N/A

\section{Competing interests}

The authors declare that they have no competing interests.

Received: 12 August 2020 Accepted: 23 October 2020

Published online: 03 November 2020

\section{References}

1. Salomão M, Hoffling-Lima AL, Lopes B, Belin MW, Sena N, Dawson DG, et al. Recent developments in keratoconus diagnosis. Exp Rev Ophthalmol. 2018; 13(6):329-41.

2. Zhang M, Zhang F, Li Y, Song Y, Wang Z. Early diagnosis of Keratoconus in Chinese myopic eyes by combining Corvis ST with Pentacam. Curr Eye Res. 2020;45(2):118-23.

3. Ortiz D, Pinero D, Shabayek MH, Arnalich-Montiel F, Alio JL. Corneal biomechanical properties in normal, post-laser in situ keratomileusis, and keratoconic eyes. J Cataract Refract Surg. 2007;33(8):1371-5.

4. Miki A, Yasukura Y, Weinreb RN, Yamada T, Koh S, Asai T, et al. Dynamic Scheimpflug ocular biomechanical parameters in healthy and medically controlled Glaucoma eyes. J Glaucoma. 2019;28(7):588-92.

5. Vinciguerra R, Rehman S, Vallabh NA, Batterbury M, Czanner G, Choudhary A, et al. Corneal biomechanics and biomechanically corrected intraocular pressure in primary open-angle glaucoma, ocular hypertension and controls. Br J Ophthalmol. 2020;104(1):121-6.

6. Ethier $\mathrm{CR}$, Johnson $\mathrm{M}$, Ruberti J. Ocular biomechanics and biotransport. Annu Rev Biomed Eng. 2004;6:249-73.

7. Elsheikh A, Wang D, Brown M, Rama P, Campanelli M, Pye D. Assessment of corneal biomechanical properties and their variation with age. Curr Eye Res. 2007:32(1):11-9.

8. Hon Y, Chen GZ, Lu SH, Lam DC, Lam AK. In vivo measurement of regional corneal tangent modulus. Sci Rep. 2017;7(1):14974.

9. Salmi A, Nieminen HJ, Veira Canle D, Haeggstrom E, Kontiola A. Non-contact determination of intra-ocular pressure in an ex vivo porcine model. PLoS One. 2020;15(2):e0227488.

10. Eliasy A, Chen KJ, Vinciguerra R, Lopes BT, Abass A, Vinciguerra P, et al. Determination of corneal biomechanical behavior in-vivo for healthy eyes using CorVis ST tonometry: stress-strain index. Front Bioeng Biotechnol. 2019;7:105.

11. Ruberti JW, Sinha Roy A, Roberts CJ. Corneal biomechanics and biomaterials. Annu Rev Biomed Eng. 2011;13:269-95.

12. Clayson K, Pan X, Pavlatos E, Short R, Morris H, Hart RT, et al. Corneoscleral stiffening increases IOP spike magnitudes during rapid microvolumetric change in the eye. Exp Eye Res. 2017;165:29-34.

13. Chua J, Nongpiur ME, Zhao W, Tham YC, Gupta P, Sabanayagam C, et al. Comparison of corneal biomechanical properties between Indian and Chinese adults. Ophthalmology. 2017;124(9):1271-9.

14. Kotecha A, Elsheikh A, Roberts CR, Zhu H, Garway-Heath DF. Corneal thickness- and age-related biomechanical properties of the cornea measured with the ocular response analyzer. Invest Ophthalmol Vis Sci. 2006;47(12):5337-47

15. Cui $X$, Yang $Y$, Li Y, Huang F, Zhao Y, Chen H, et al. Correlation between anterior chamber volume and corneal biomechanical properties in human eyes. Front Bioeng Biotechnol. 2019;7:379.

16. Tubtimthong A, Chansangpetch S, Ratprasatporn N, Manassakorn A Tantisevi V, Rojanapongpun P, et al. Comparison of corneal biomechanical properties among axial myopic, nonaxial myopic, and nonmyopic eyes. Biomed Res Int. 2020;2020:8618615.

17. Vinciguerra R, Ambrosio R Jr, Roberts CJ, Azzolini C, Vinciguerra P. Biomechanical characterization of subclinical Keratoconus without topographic or tomographic abnormalities. J Refract Surg. 2017;33(6): 399-407. 
18. Nemeth G, Szalai E, Hassan Z, Lipecz A, Flasko Z, Modis L. Corneal biomechanical data and biometric parameters measured with Scheimpflugbased devices on normal corneas. Int J Ophthalmol. 2017;10(2):217-22.

19. Lim L, Gazzard G, Chan YH, Fong A, Kotecha A, Sim EL, et al. Cornea biomechanical characteristics and their correlates with refractive error in Singaporean children. Invest Ophthalmol Vis Sci. 2008;49(9):3852-7.

20. Wang W, He M, He H, Zhang C, Jin H, Zhong X. Corneal biomechanical metrics of healthy Chinese adults using Corvis ST. Cont Lens Anterior Eye. 2017;40(2):97-103.

21. Daxer A, Misof K, Grabner B, Ettl A, Fratzl P. Collagen fibrils in the human corneal stroma: structure and aging. Invest Ophthalmol Vis Sci. 1998;39(3): 644-8.

22. Malik NS, Moss SJ, Ahmed N, Furth AJ, Wall RS, Meek KM. Ageing of the human corneal stroma: structural and biochemical changes. Biochim Biophys Acta. 1992;1138(3):222-8.

23. Blackburn BJ, Jenkins MW, Rollins AM, Dupps WJ. A review of structural and biomechanical changes in the cornea in aging, disease, and photochemical crosslinking. Front Bioeng Biotechnol. 2019;7:66.

24. Kirwan C, O'Keefe M, Lanigan B. Corneal hysteresis and intraocular pressure measurement in children using the reichert ocular response analyzer. Am J Ophthalmol. 2006;142(6):990-2.

25. He M, Ding H, He H, Zhang C, Liu L, Zhong X. Corneal biomechanical properties in healthy children measured by corneal visualization scheimpflug technology. BMC Ophthalmol. 2017;17(1):70.

26. Valbon BF, Ambrosio R Jr, Fontes BM, Alves MR. Effects of age on corneal deformation by non-contact tonometry integrated with an ultra-high-speed (UHS) Scheimpflug camera. Arq Bras Oftalmol. 2013;76(4):229-32.

27. Elsheikh A, Geraghty B, Rama P, Campanelli M, Meek KM. Characterization of age-related variation in corneal biomechanical properties. J R Soc Interface. 2010;7(51):1475-85.

28. Parssinen $\mathrm{O}$, Kauppinen M, Viljanen A. The progression of myopia from its onset at age 8-12 to adulthood and the influence of heredity and external factors on myopic progression. A 23-year follow-up study. Acta Ophthalmol. 2014;92(8):730-9.

29. Ohno-Matsui K, Akiba M, Ishibashi T, Moriyama M. Observations of vascular structures within and posterior to sclera in eyes with pathologic myopia by swept-source optical coherence tomography. Invest Ophthalmol Vis Sci. 2012;53(11):7290-8.

30. Jonas JB, Xu L. Histological changes of high axial myopia. Eye (Lond). 2014; 28(2):113-7

31. Harper AR, Summers JA. The dynamic sclera: extracellular matrix remodeling in normal ocular growth and myopia development. Exp Eye Res. 2015;133: 100-11.

32. Morgan SR, Dooley EP, Hocking PM, Inglehearn CF, Ali M, Sorensen TL, et al. An $x$-ray scattering study into the structural basis of corneal refractive function in an avian model. Biophys J. 2013;104(12):2586-94.

33. Kee CS, Hung LF, Qiao-Grider Y, Ramamirtham R, Smith EL 3rd. Astigmatism in monkeys with experimentally induced myopia or hyperopia. Optom Vis Sci. 2005:82(4):248-60.

34. Hayes BP, Fitzke FW, Hodos W, Holden AL. A morphological analysis of experimental myopia in young chickens. Invest Ophthalmol Vis Sci. 1986; 27(6):981-91.

35. Chang SW, Tsai IL, Hu FR, Lin LL, Shih YF. The cornea in young myopic adults. Br J Ophthalmol. 2001;85(8):916-20

36. Chansangpetch S, Panpruk R, Manassakorn A, Tantisevi V, Rojanapongpun P, Hurst CP, et al. Impact of myopia on corneal biomechanics in Glaucoma and nonglaucoma patients. Invest Ophthalmol Vis Sci. 2017;58(12):4990-6.

37. Matalia J, Francis M, Gogri P, Panmand P, Matalia H, Sinha RA. Correlation of corneal biomechanical stiffness with refractive error and ocular biometry in a pediatric population. Cornea. 2017;36(10):1221-6.

38. Long W, Zhao Y, Hu Y, Li Z, Zhang X, Zhao W, et al. Characteristics of corneal biomechanics in Chinese preschool children with different refractive status. Cornea. 2019;38(11):1395-9.

39. Liu J, Roberts CJ. Influence of corneal biomechanical properties on intraocular pressure measurement: quantitative analysis. J Cataract Refract Surg. 2005;31(1):146-55.

40. Joda AA, Shervin MM, Kook D, Elsheikh A. Development and validation of a correction equation for Corvis tonometry. Comput Methods Biomech Biomed Eng. 2016;19(9):943-53.

41. Fernandez J, Rodriguez-Vallejo M, Martinez J, Tauste A, Salvestrini P, Pinero DP. New parameters for evaluating corneal biomechanics and intraocular pressure after small-incision lenticule extraction by Scheimpflug-based dynamic tonometry. J Cataract Refract Surg. 2017:43(6):803-11.

42. Eliasy A, Chen KJ, Vinciguerra R, Maklad O, Vinciguerra P, Ambrosio R Jr, et al. Ex-vivo experimental validation of biomechanically-corrected intraocular pressure measurements on human eyes using the CorVis ST. Exp Eye Res. 2018;175:98-102.

43. Ma J, Wang Y, Hao W, Jhanji V. Comparative analysis of biomechanically corrected intraocular pressure with corneal visualization Scheimpflug technology versus conventional noncontact intraocular pressure. Int Ophthalmol. 2020;40(1):117-24

44. Matsuura M, Murata H, Fujino $Y$, Yanagisawa M, Nakao $Y$, Tokumo K, et al. Relationship between novel intraocular pressure measurement from Corvis ST and central corneal thickness and corneal hysteresis. Br J Ophthalmol. 2020;104(4):563-8

45. Hwang HS, Park SK, Kim MS. The biomechanical properties of the cornea and anterior segment parameters. BMC Ophthalmol. 2013;13:49.

46. Zhang Y, Wang Y, Li L, Dou R, Wu W, Wu D, et al. Corneal stiffness and its relationship with other corneal biomechanical and nonbiomechanical parameters in myopic eyes of Chinese patients. Cornea. 2018;37(7):881-5.

47. Gonzalez-Meijome JM, Villa-Collar C, Queiros A, Jorge J, Parafita MA. Pilot study on the influence of corneal biomechanical properties over the short term in response to corneal refractive therapy for myopia. Cornea. 2008; 27(4):421-6

48. Souza MB, de Medeiros FW, Villela FF, Alves MR. Relationship between the biomechanical properties of the cornea and anterior segment measurements. Clinics (Sao Paulo). 2018;73:e491.

49. Horner DG, Soni PS, Vyas N, Himebaugh NL. Longitudinal changes in corneal asphericity in myopia. Optom Vis Sci. 2000;77(4):198-203.

\section{Publisher's Note}

Springer Nature remains neutral with regard to jurisdictional claims in published maps and institutional affiliations.

Ready to submit your research? Choose BMC and benefit from:

- fast, convenient online submission

- thorough peer review by experienced researchers in your field

- rapid publication on acceptance

- support for research data, including large and complex data types

- gold Open Access which fosters wider collaboration and increased citations

- maximum visibility for your research: over $100 \mathrm{M}$ website views per year

At $\mathrm{BMC}$, research is always in progress.

Learn more biomedcentral.com/submissions 